\title{
A spatial decision support system for guiding focal indoor residual spraying interventions in a malaria elimination zone
}

\author{
Gerard C. Kelly ${ }^{1}$, Chang Moh Seng ${ }^{2}$, Wesley Donald ${ }^{3}$, George Taleo ${ }^{3}$, Johnny Nausien ${ }^{3}$, Willie \\ Batarii ${ }^{4}$, Harry Iata ${ }^{3}$, Marcel Tanner ${ }^{5,6}$, Lasse S. Vestergaard ${ }^{2}$, Archie C. A. Clements ${ }^{1}$ \\ ${ }^{1}$ University of Queensland, School of Population Health, Brisbane, Australia; ${ }^{2}$ World Health Organization, \\ Country Liaison Office, Port Vila, Vanuatu; ${ }^{3}$ Ministry of Health, Vector Borne Disease Control Programme, \\ Port Vila, Vanuatu; ${ }^{4}$ Ministry of Health and Medical Services, Vector Borne Disease Control Programme, \\ Honiara, Solomon Islands; ${ }^{5}$ Swiss Tropical and Public Health Institute, Basel, Switzerland; ${ }^{6}$ University of Basel, \\ Basel, Switzerland
}

\begin{abstract}
A customized geographical information system (GIS) has been developed to support focal indoor residual spraying (IRS) operations as part of a scaled-up campaign to progressively eliminate malaria in Vanuatu. The aims of the GISbased spatial decision support system (SDSS) were to guide the planning, implementation and assessment of IRS at the household level. Additional aims of this study were to evaluate the user acceptability of a SDSS guiding IRS interventions. IRS was conducted on Tanna Island, Republic of Vanuatu between 26 October and 5 December 2009. Geo-referenced household information provided a baseline within the SDSS. An interactive mapping interface was used to delineate operation areas, extract relevant data to support IRS field teams. In addition, it was used as a monitoring tool to assess overall intervention coverage. Surveys and group discussions were conducted during the operations to ascertain user acceptability. Twenty-one operation areas, comprising a total of 187 settlements and 3,422 households were identified and mapped. A total of 3,230 households and 12,156 household structures were sprayed, covering a population of 13,512 individuals, achieving coverage of $94.4 \%$ of the households and $95.7 \%$ of the population. Village status maps were produced to visualize the distribution of IRS at the sub-village level. One hundred percent of survey respondents declared the SDSS a useful and effective tool to support IRS. The GIS-based SDSS adopted in Tanna empowered programme managers at the provincial level to implement and asses the IRS intervention with the degree of detail required for malaria elimination. Since completion, SDSS applications have expanded to additional provinces in Vanuatu and the neighbouring Solomon Islands supporting not only specific malaria elimination and control interventions, but also the broader public health sector in general.
\end{abstract}

Keywords: geographical information system, malaria elimination, indoor residual spraying, spatial decision support system, Republic of Vanuatu.

\section{Introduction}

Of the current 99 countries with endemic malaria, 32 have now committed to some kind of elimination strategy (Feachem et al., 2010). Key strategies to support the eventual eradication of malaria have been outlined in the Roll Back Malaria (RBM) Global Malaria Action Plan (GMAP) and focus on three major approaches (GMAP, 2008; Feachem et al., 2009, 2010). These include: (i) aggressive and sustained malaria control in highly endemic countries; (ii) progressive malaria elimination from the endem-

\footnotetext{
Corresponding author:

Gerard C. Kelly

University of Queensland, School of Population Health

Brisbane, Australia

Tel. +61 0423443 932; Fax +610 266531245

E-mail: gerardckelly@gmail.com
}

ic margins inward (i.e. shrinking the malaria map); and (iii) continued research into new tools, approaches and interventions for malaria control and elimination.

The Republic of Vanuatu is the southern and eastern-most malaria-endemic country in the South Pacific (Feachem et al., 2010). As part of the GMAP strategy to shrink the malaria map from the endemic margins inward, the Government of Vanuatu, with support from the Australian Agency for International Development (AusAID) and the Pacific Malaria Initiative (PacMI) programme, is currently implementing a progressive malaria elimination campaign starting in the Tafea province in southern Vanuatu. Priority interventions by programme type have been recommended by the World Health Organization (WHO) to guide elimination in countries of low and moderate endemicity (WHO, 2007). Following these guidelines, Vanuatu has committed 
to total indoor residual spray (IRS) coverage in focal "hotspot" areas as one of the primary front-line interventions during the pre-elimination programme phase.

A major obstacle to the scale-up of services in malaria-endemic countries is weak health information systems and surveillance needed to monitor the progress of effective public health responses and/or programme adjustments (Vitoria et al., 2009; Kerouedan, 2010). Additionally, the delivery of health services and key interventions in resource-poor environments at coverage levels the target population should be able to benefit from, is still a major challenge (WHO, 2009; UNICEF/UNDP/World Bank/WHO, 2010; The malERA Consultative Group on Health Systems Operational Research, 2011). During the pre-elimination stage, malaria programmes must have the capacity to implement surveillance, reporting and information systems (WHO, 2007; GMAP, 2008).

Malaria elimination is distinct from control in its requirement for the geographical targeting of resources for key interventions (Feachem et al., 2009). In the context of focal IRS for elimination in Tafea, key operational challenges include the efficient allocation of essential resources such as insecticide, equipment and manpower to remote locations. The development of an effective monitoring, surveillance and reporting mechanism to ensure that maximum household spray coverage is uniformly achieved across the entire target area is essential.

With the growing application of geographical information systems (GIS), global positioning systems (GPS) and web-based mapping technology, spatial analysis in disease management and health planning is now well established (e.g. Lozano-Fuentes et al., 2008; Clements et al., 2009; Daash et al., 2009; Srivastava et al., 2009; Reid et al., 2010). In the context of malaria elimination, the need for modernized, high-resolution mapping to support the operational management of scaled-up interventions is also recognized (The malEra Consultative Group on Monitoring Evaluation and Surveillance, 2011). A spatial decision support system (SDSS) is an integrated database management system (usually GIS-based) that provides computerised support for decision making where there is a geographic or spatial component available (Keenen, 2003). Currently, only limited research and action has been undertaken on applied applications of SDSS to guide malaria elimination (and as a mechanism strengthen health information systems in general).

Following the completion of geographical reconnaissance (GR), household mapping and enumeration operations in Tanna (Kelly et al., 2010), the Vanuatu National Vector Borne Disease Control Programme (VBDCP) is committed to exploring an SDSS approach as a mechanism to support the scaled-up demands of malaria elimination. This study focuses on the use of a customised, GIS-based SDSS to support first-round focal IRS in Tanna. The aims of the study were to develop an applied map-based tool to assist in the delineation of IRS zones to support resource allocation and deployment; to monitor and assess spray coverage by population and household throughout the intervention; and to map the respective spatial distribution of IRS service delivery at the household level. This study also provided an opportunity to evaluate the user acceptability of a SDSS in meeting the monitoring and evaluation responsibilities of a malaria elimination programme.

\section{Materials and methods}

\section{Study area}

Focal IRS was conducted on Tanna Island in province of Tafea, Republic of Vanuatu, an area selected for malaria elimination (Fig. 1). Following baseline entomological surveys to describe the distribution of the vector Anopheles farauti (The PacMI Survey Group on behalf of the Ministries of Health of Vanuatu and Solomon Islands, 2010) and geo-statistical analysis of malaria survey data on the main island of Tanna in 2008 (Reid et al., 2010), focal IRS operational areas on Tanna was defined as all settlements located within a $2 \mathrm{~km}$ boundary of the coastline. As part of the Tafea province elimination strategy, three annual rounds of IRS were planned for the Tanna focal IRS zone between 2009 and 2011. The first round of IRS, consisting of a main spraying campaign immediately followed up to cover households not reached by the initial round, was conducted between 26 October and 5 December, 2009.

Approval to conduct IRS was provided by the Vanuatu Ministry of Health $(\mathrm{MoH})$. Ethical approval was not sought during this study as IRS is considered a routine operational activity of the national malaria programme, with all collected data managed as per confidentiality requirements of the Vanuatu MoH. All IRS fieldwork was conducted by VBDCP staff and casual employees contracted by the $\mathrm{MoH}$ with training and technical assistance provided by WHO and the PacMI Support Centre (PacMISC). 


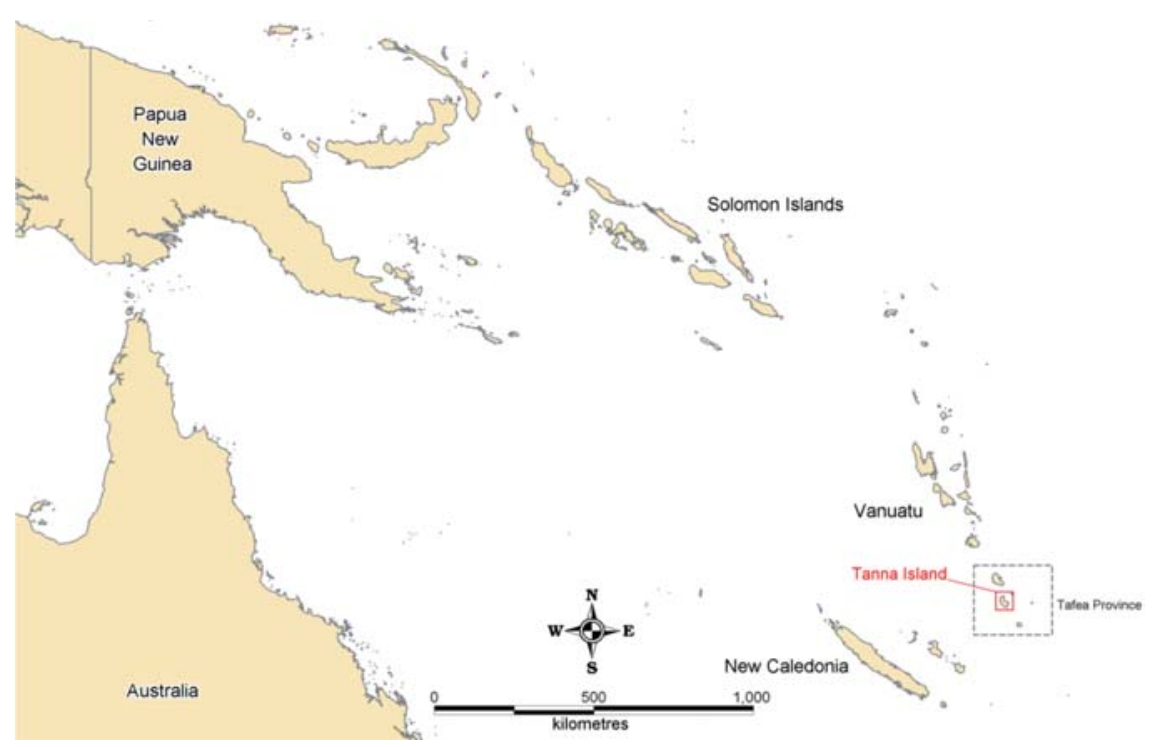

Fig. 1. Location of Tanna Island, Vanuatu.

\section{Spatial decision support system development}

MapInfo Professional and MapBasic (Pitney Bowes Software Inc., Troy, NY, USA) were used as the GIS software platform of the SDSS and for the development of customized SDSS application within the GIS, respectively. Microsoft Excel and Microsoft Access (Microsoft Corporation, Redmond, WA, USA) software were used for additional integrated data management and analysis. Topographic and household data previously acquired during GR (Kelly et al., 2010) provided the basis for the geospatial IRS man- agement framework. These included detailed population and building structure data collected by household. Hydrographic, altitude, road and other infrastructure data were also acquired from relevant partner ministries to provide baseline topographic information. Specific applications developed within the SDSS were designed to provide interactive and automated support for key components of IRS management including planning, implementation, monitoring, and reporting. Table 1 provides a breakdown of the specific technical applications developed within the SDSS.

Table 1. Technical components of the indoor residual spraying (IRS) customised spatial decision support system (SDSS).

\begin{tabular}{|c|c|c|}
\hline $\begin{array}{l}\text { IRS management } \\
\text { component }\end{array}$ & SDSS technical function & Application for the IRS intervention \\
\hline \multirow{3}{*}{ Planning } & GIS buffering to define focal IRS zone & Develop a map of the $2 \mathrm{~km}$ coastal IRS zone \\
\hline & Interactive mapping to define operation areas & $\begin{array}{l}\text { Used to breakdown and map the IRS zone } \\
\text { into smaller manageable areas }\end{array}$ \\
\hline & $\begin{array}{l}\text { Automated query to extract household, spray-able structure } \\
\text { and population summary data by operation area }\end{array}$ & $\begin{array}{l}\text { Application to provide summary details of the operation } \\
\text { area to support the planning of required resources and } \\
\text { timeframes }\end{array}$ \\
\hline \multirow{2}{*}{ Implementation } & $\begin{array}{l}\text { Automatic generation of IRS hardcopy checklists by } \\
\text { household }\end{array}$ & $\begin{array}{l}\text { Application to provide detailed checklists for } \\
\text { IRS field teams }\end{array}$ \\
\hline & $\begin{array}{l}\text { Interactive operation area household location mapping } \\
\text { application }\end{array}$ & $\begin{array}{l}\text { Development of operation area maps to aid } \\
\text { IRS field teams }\end{array}$ \\
\hline \multirow{3}{*}{ Monitoring } & $\begin{array}{l}\text { Automatic IRS status thematic mapping from hardcopy } \\
\text { checklist data }\end{array}$ & $\begin{array}{l}\text { Used to monitor the progress of IRS in the field at the } \\
\text { household level via a map interface }\end{array}$ \\
\hline & Automatic generation of IRS follow-up lists by household & $\begin{array}{l}\text { Application to extract a detailed list of households not } \\
\text { sprayed during the initial round }\end{array}$ \\
\hline & Interactive IRS household follow-up mapping application & $\begin{array}{l}\text { Development of follow-up maps highlighting } \\
\text { households not sprayed }\end{array}$ \\
\hline \multirow[t]{2}{*}{ Reporting } & $\begin{array}{l}\text { Automated IRS status summary reports via Microsoft } \\
\text { Access interface }\end{array}$ & Development of reports to measure IRS coverage \\
\hline & Automated IRS status thematic map generation & Development of IRS coverage spatial distribution maps \\
\hline
\end{tabular}




\section{Spatial decision support system operations training}

Development of the customized SDSS took place at the provincial level in consultation with Vanuatu VBDCP malaria information officers and the Tafea province malaria supervisor. As part of an introduction into the customized SDSS system for IRS management, standard operating procedures (SOPs) were developed and technical training provided to the national and Tafea VBDCP malaria information officers over a 3-day period. Following the initial introduction and training period, the SDSS was operated independently by the national and provincial VBDCP information officers throughout the first round of IRS interventions.

\section{Implementation of IRS}

The pre-defined focal IRS zone was mapped in the GIS to produce a polygon layer of all inland areas within a $2-\mathrm{km}$ boundary of the coastline. All geo-referenced household information collected during GR and household mapping operations was then extracted to provide a total summary of the IRS target area by household and population. Prior to the deployment of IRS field teams, surface areas of all indoor surfaces deemed spray-able were estimated from a selection of 40 households (10 per individual health zone on Tanna) to allow calculating insecticide volume requirements.

The 2-km coastal IRS zone was broken down into individual operational areas to support the planning and allocation of required resources and deployment of field teams. Using the customized SDSS application, area boundaries were defined and digitally mapped by VBDCP personnel based on the spatial distribution of households, terrain, logistical constraints and existing local knowledge of the IRS focal zone. Household, spray-able structures and population summary data were automatically generated as area boundaries were defined to assist the estimation of resources needed.

Eighteen IRS field teams consisting of four individuals per team were used to carry-out IRS. These teams were managed by one overall IRS coordinator and three field supervisors. One provincial information officer was responsible for the monitoring and evaluation of the IRS and supported by the national-based VBDCP information officer as required. Household spray lists were extracted using the SDSS and exported into hardcopy templates, providing household checklists for IRS field teams. Hardcopy checklists provided the teams with detailed household informa- tion including: (i) a unique household identification number; (ii) name of the household head; (iii) the household population; (iv) the village name; and (v) a detailed breakdown of the number and type of sprayable structures per household. Additional fields were added to the hardcopy checklist to record IRS progress including: (i) number and type of structures sprayed per household; (ii) IRS household spray status; and (iii) additional comments field to record reasons for households remaining "not sprayed" or "partially sprayed". Household location maps were produced for each IRS operation area to provide a simple navigational tool to assist spray teams to locate households whilst in the field. IRS teams were issued hardcopy household checklists and location maps, and briefed on their correct usage prior to commencing field operations.

\section{Monitoring the progress of IRS}

All household checklist information was updated into a centralized spreadsheet prior to the commencement of IRS. As these were completed, hardcopy checklists were sent to the provincial headquarters for data entry. All data entry was carried out by the provincial information officers concurrently with IRS field operations. As the IRS data were updated, the household spray status was thematically mapped through an automated application. Following the completion of the initial first-round IRS, hard-copy lists of all households not sprayed were automatically generated and re-issued to spray teams to conduct the follow-up campaign. Maps of households not sprayed were produced to provide a navigational aid for the field teams. Upon completion, follow-up household spray data were entered into the spreadsheet as per the first-round operations and automatically updated into the SDSS.

\section{Assessment of SDSS management framework}

Basic descriptive statistics of selected indicators were used to analyse the data generated by the SDSS and to assess IRS coverage at the completion of both first-round and follow-up IRS. These data included: (i) total number of settlements visited; (ii) total number of households visited; (iii) total population; (iv) number of households sprayed; (v) total population covered; (vi) number of household refusals; (vii) percentage of household spray coverage; and (viii) percentage of population coverage. Automated SDSS data reports were generated via a Microsoft Access 
interface to provide routine feedback regarding progress during the intervention and an overall summary of the first-round IRS. Coverage maps were also produced.

Operational SDSS errors were monitored throughout the course of the intervention in Tanna. SDSS user acceptability surveys based on a five-point Likert scale (1932) range and open response were also administered to VBDCP information officers, IRS coordinators and supervisors. To increase the number of SDSS operators providing data for analysis, we also administered surveys to the relevant VBDCP staff in the Solomon Islands, where a similar SDSS-based approach to IRS had been adopted. A total of 12 SDSS user acceptability surveys were administered in Vanuatu and the Solomon Islands. Post-fieldwork debrief sessions were also conducted with all IRS field teams to interview participants about their individual experiences and perceptions of the SDSS framework and associated applications. Additionally, participants were also asked to give insight into potential improvements and additional applications relevant to the malaria elimination programme in Tafea.

\section{Results}

Twenty-one IRS operation areas, comprising a total of 187 settlements and 3,422 households, were defined and mapped by the provincial VBDCP malaria information officer using the interactive SDSS mapping interface (Fig. 2). Table 2 shows the target number of households, sprayable structures and population in each IRS operation area, generated by the SDSS and used to guide IRS planning and resource allocation. Fig. 3 provides a screenshot of the IRS planning SDSS interface used to generate the IRS household spray lists and operation area summaries.

\section{Summary of first-round IRS interventions}

A total of 3,015 households and 11,737 household structures were sprayed following the initial round of IRS, covering a population of 12,762 individuals. The initial first-round spray coverage was $88.1 \%$ of households and $91.3 \%$ of household structures, covering $90.4 \%$ of the population. Following the completion of follow-up IRS, a total of 3,230 households and 12,156 household structures were sprayed, covering a population of 13,512 individuals. The final, first-round IRS spray coverage was recorded as $94.4 \%$ of households and $94.6 \%$ household structures, covering $95.7 \%$ of the population. Fig. 4 illustrates the spatial distribu- tion of IRS coverage on Tanna at the completion of both the initial main round and follow-up IRS stages. Table 3 provides a breakdown of IRS coverage data by health zone following the completion of first-round interventions. Table 4 also provides a breakdown of household structures by type sprayed during first-

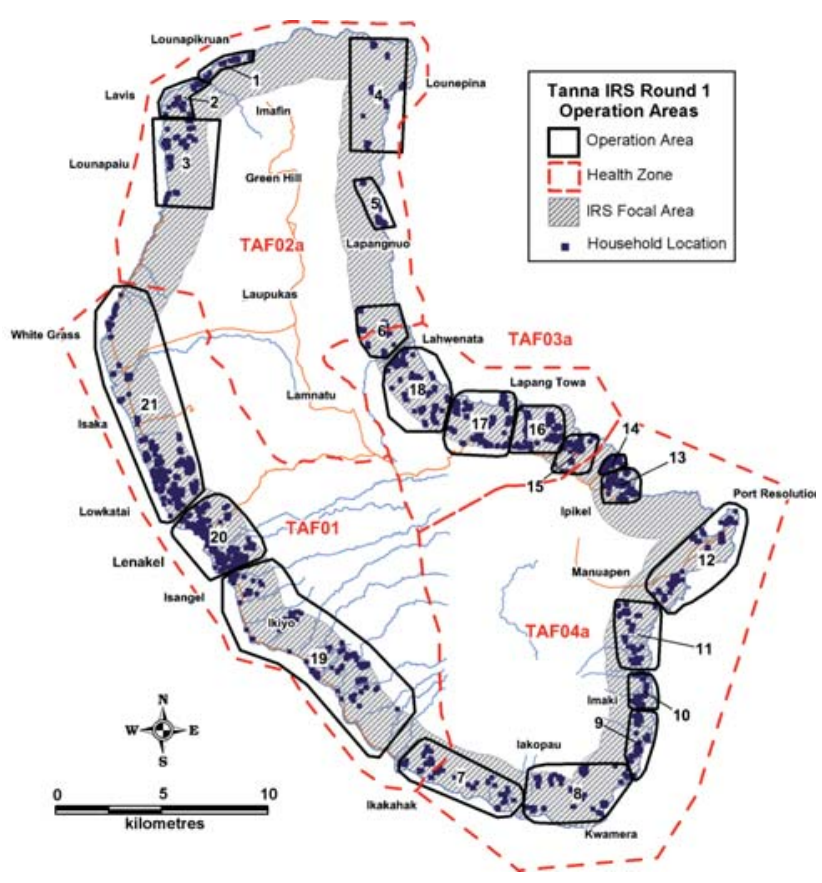

Fig. 2. Tanna Island IRS operation areas map.

Table 2. Operation area summary data generated by the customised SDSS.

\begin{tabular}{ccccc}
\hline $\begin{array}{c}\text { Operation } \\
\text { zone }\end{array}$ & $\begin{array}{c}\text { Total } \\
\text { settlements }\end{array}$ & $\begin{array}{c}\text { Total } \\
\text { households }\end{array}$ & $\begin{array}{c}\text { Sprayable } \\
\text { structures }\end{array}$ & $\begin{array}{c}\text { Total } \\
\text { population }\end{array}$ \\
\hline 1 & 3 & 52 & 193 & 227 \\
2 & 1 & 53 & 206 & 216 \\
3 & 2 & 93 & 328 & 361 \\
4 & 4 & 73 & 228 & 339 \\
5 & 3 & 49 & 136 & 210 \\
6 & 7 & 52 & 179 & 205 \\
7 & 7 & 106 & 380 & 543 \\
8 & 9 & 123 & 457 & 523 \\
9 & 7 & 95 & 339 & 431 \\
10 & 6 & 83 & 295 & 367 \\
11 & 8 & 108 & 365 & 420 \\
12 & 5 & 158 & 534 & 609 \\
13 & 6 & 198 & 611 & 779 \\
14 & 7 & 124 & 434 & 427 \\
15 & 3 & 104 & 418 & 388 \\
16 & 10 & 207 & 754 & 825 \\
17 & 14 & 267 & 1054 & 1,075 \\
18 & 11 & 194 & 662 & 802 \\
19 & 23 & 228 & 1,041 & 1,048 \\
20 & 25 & 514 & 2,226 & 2,294 \\
21 & 26 & 541 & 2,013 & 2,030 \\
Total & 187 & 3,422 & 12,853 & 14,119 \\
\hline
\end{tabular}




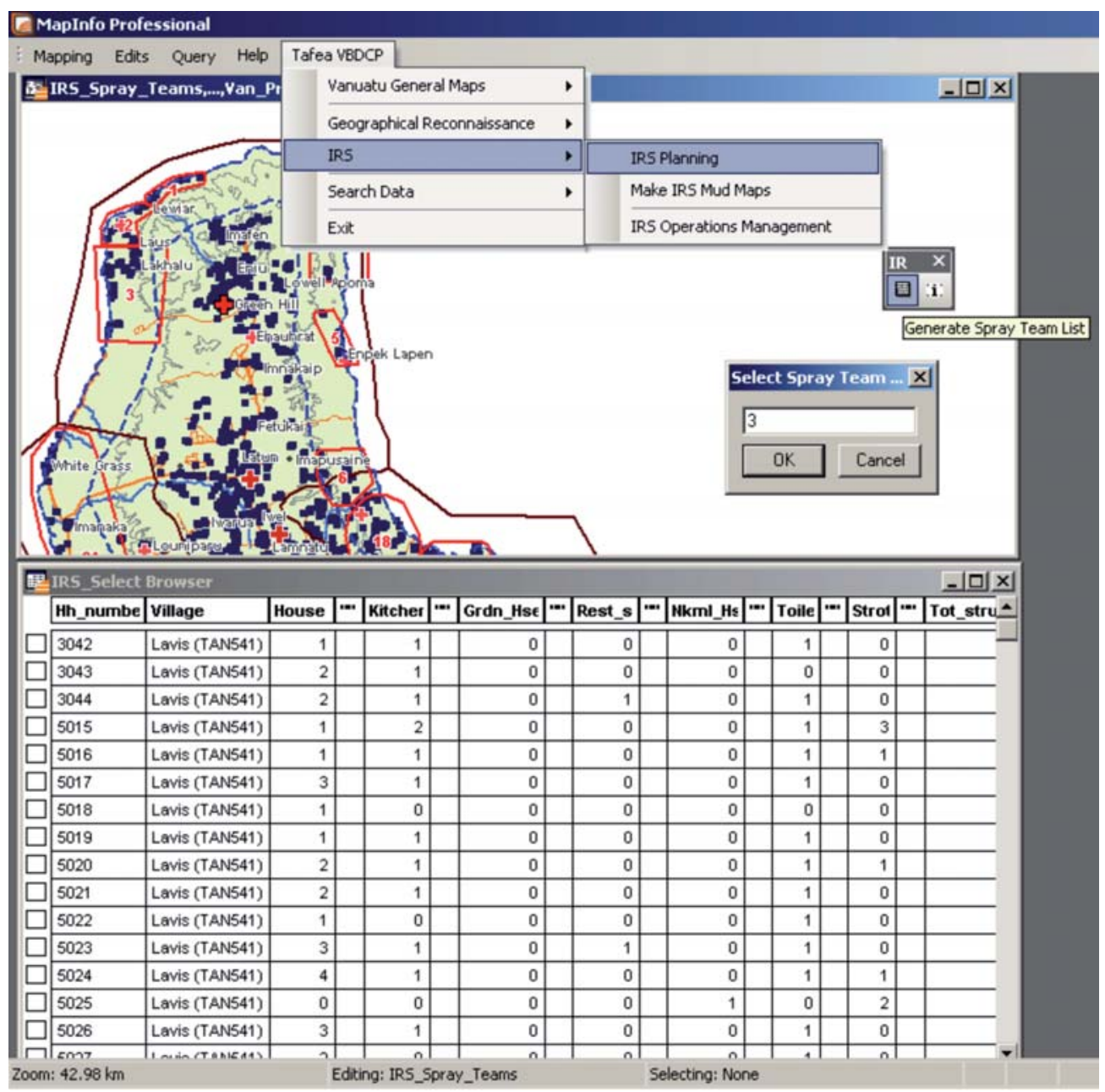

Fig. 3. Screenshot of the IRS planning SDSS application.

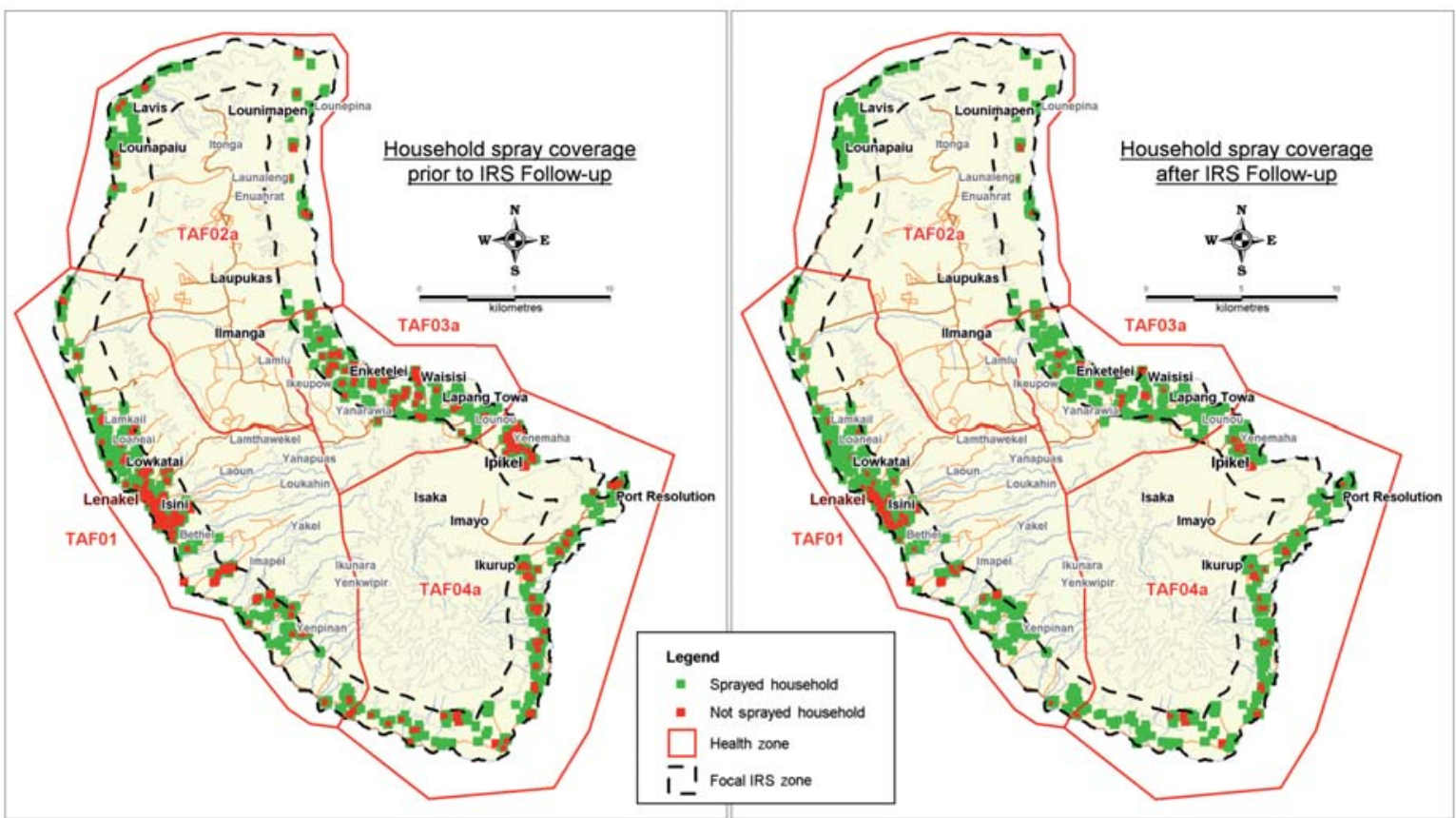

Fig. 4. Spatial distribution of IRS coverage prior to and following the first-round follow-up operations. 
Table 3. Tanna Island first-round IRS coverage, stratified by health zone

\begin{tabular}{|c|c|c|c|c|c|c|c|c|c|}
\hline \multirow{2}{*}{$\begin{array}{l}\text { Health } \\
\text { zone }\end{array}$} & \multirow{2}{*}{$\begin{array}{l}\text { Settlements } \\
\text { visited }\end{array}$} & \multicolumn{2}{|c|}{ Total recorded } & \multicolumn{2}{|c|}{ Sprayed (initial round) } & \multicolumn{2}{|c|}{ Sprayed (follow-up) } & \multicolumn{2}{|c|}{ Total sprayed } \\
\hline & & Households & Population & Households & Population & Households & Population & Households & Population \\
\hline TAF 01 & 74 & 1,283 & 5,372 & $\begin{array}{l}87.1 \% \\
(1,118)\end{array}$ & $\begin{array}{l}90.5 \% \\
(4,861)\end{array}$ & $\begin{array}{c}6.2 \% \\
(79)\end{array}$ & $\begin{array}{l}5.3 \% \\
(284)\end{array}$ & $\begin{array}{l}93.3 \% \\
(1,197)\end{array}$ & $\begin{array}{l}95.8 \% \\
(5,145)\end{array}$ \\
\hline TAF $02 \mathrm{a}$ & 20 & 372 & 1,558 & $\begin{array}{c}95.2 \% \\
(354)\end{array}$ & $\begin{array}{l}95.4 \% \\
(1,487)\end{array}$ & $\begin{array}{c}3.2 \% \\
(12)\end{array}$ & $\begin{array}{c}2.6 \% \\
(41)\end{array}$ & $\begin{array}{c}98.4 \% \\
(366)\end{array}$ & $\begin{array}{l}98.1 \% \\
(1,528)\end{array}$ \\
\hline TAF 03a & 38 & 772 & 3,090 & $\begin{array}{c}89.9 \% \\
(694)\end{array}$ & $\begin{array}{l}91.5 \% \\
(2,826)\end{array}$ & $\begin{array}{c}6.5 \% \\
(50)\end{array}$ & $\begin{array}{l}5.5 \% \\
(171)\end{array}$ & $\begin{array}{c}96.4 \% \\
(744)\end{array}$ & $\begin{array}{l}97.00 \% \\
(2,997)\end{array}$ \\
\hline TAF 04a & 55 & 995 & 4,099 & $\begin{array}{c}85.3 \% \\
(849)\end{array}$ & $\begin{array}{l}87.5 \% \\
(3,588)\end{array}$ & $\begin{array}{c}7.4 \% \\
(74)\end{array}$ & $\begin{array}{l}6.2 \% \\
(254)\end{array}$ & $\begin{array}{c}92.8 \% \\
(923)\end{array}$ & $\begin{array}{l}93.7 \% \\
(3,842)\end{array}$ \\
\hline Total & 187 & 3,422 & 14,119 & $\begin{array}{l}88.1 \% \\
(3,015)\end{array}$ & $\begin{array}{l}90.4 \% \\
12,762)\end{array}$ & $\begin{array}{l}6.3 \% \\
(215)\end{array}$ & $\begin{array}{l}5.3 \% \\
(750)\end{array}$ & $\begin{array}{l}94.4 \% \\
(3,230)\end{array}$ & $\begin{array}{c}95.7 \% \\
(13,512)\end{array}$ \\
\hline
\end{tabular}

round IRS activities. Fig. 5 provides a screenshot of the SDSS monitoring application used to generate household follow-up spray lists has been provided as an additional file.

Only 192 of the 3,422 recorded households were not sprayed at the completion of the follow-up IRS round on Tanna. Table 5 shows the main reasons for houses not sprayed. Seventy-five refusals and 73 locked households were recorded, attributing to $39.1 \%$ and $38.0 \%$ of total households not sprayed, respectively. Other reasons households were not sprayed included households serving as food store or canteen, general inaccessibility and because of sick residents. Fig. 6 shows an example of an IRS village status map visualizing the spatial distribution of households not sprayed to identify any clustering at the subvillage level, both during and after completion of the initial and the follow-up rounds of IRS.

Prior to the commencement of IRS, the average household surface area was estimated at $168 \mathrm{~m}^{2}$. The first-round IRS operations used 2,760 ICON ${ }^{\circledR}$ 10CS insecticide sachets $(62.5 \mathrm{ml}$ per sachet containing $10 \%$ active ingredient) indicating total insecticide consumption at 172.5 litres. Based on the average household surface area and the number of total households sprayed, the insecticide dosage rates were estimated at $28 \mathrm{mg}$ active ingredient $/ \mathrm{m}^{2}$, falling within the WHO pesticide evaluation scheme (WHOPES) recommended dosage of $20-30 \mathrm{mg}$ active ingredient $/ \mathrm{m}^{2}$ (WHO, 2009).

\section{Assessment of the SDSS management framework}

During the planning and implementation of the IRS rounds on Tanna, no operational errors relating to use of the SDSS system by the IRS teams were identified or reported. The acceptability among the users of the SDSS was excellent, with $12 / 12(100 \%)$ respondents of the acceptability questionnaire stating that the SDSS is a useful and effective tool for planning, monitoring and reporting of IRS (Table 6). Common themes highlighted from additional comments and mentioned during debriefing with IRS personnel were centred on interest in employing the SDSS application in the malaria control provinces where IRS is currently implemented or planned, and the need to continue developing the SDSS to support additional priority interventions specific to malaria elimination.

Table 4. IRS coverage breakdown by household structure.

\begin{tabular}{|c|c|c|c|c|c|c|}
\hline Structure type & Total recorded & $\begin{array}{l}\text { Sprayed in } \\
\text { first-round }\end{array}$ & $\begin{array}{l}\text { Sprayed (\%) } \\
\text { (first-round) }\end{array}$ & $\begin{array}{l}\text { Sprayed during } \\
\text { follow-up }\end{array}$ & Total sprayed & $\begin{array}{c}\text { Sprayed }(\%) \\
\text { (final) }\end{array}$ \\
\hline Sleeping house & 4,895 & 4,489 & 91.7 & 171 & 4,660 & 95.2 \\
\hline Kitchen & 2,689 & 2,492 & 92.7 & 74 & 2,566 & 95.4 \\
\hline Garden house & 15 & 14 & 93.3 & 0 & 14 & 93.3 \\
\hline Rest shelter & 748 & 687 & 91.8 & 14 & 701 & 93.7 \\
\hline Nakamal & 255 & 219 & 85.9 & 10 & 229 & 89.8 \\
\hline Toilet & 2,182 & 2,022 & 92.7 & 51 & 2,073 & 95.0 \\
\hline Other structures & 2,069 & 1,814 & 87.7 & 99 & 1,913 & 92.5 \\
\hline Total & 12,853 & 11,737 & 91.3 & 419 & 12,156 & 94.6 \\
\hline
\end{tabular}




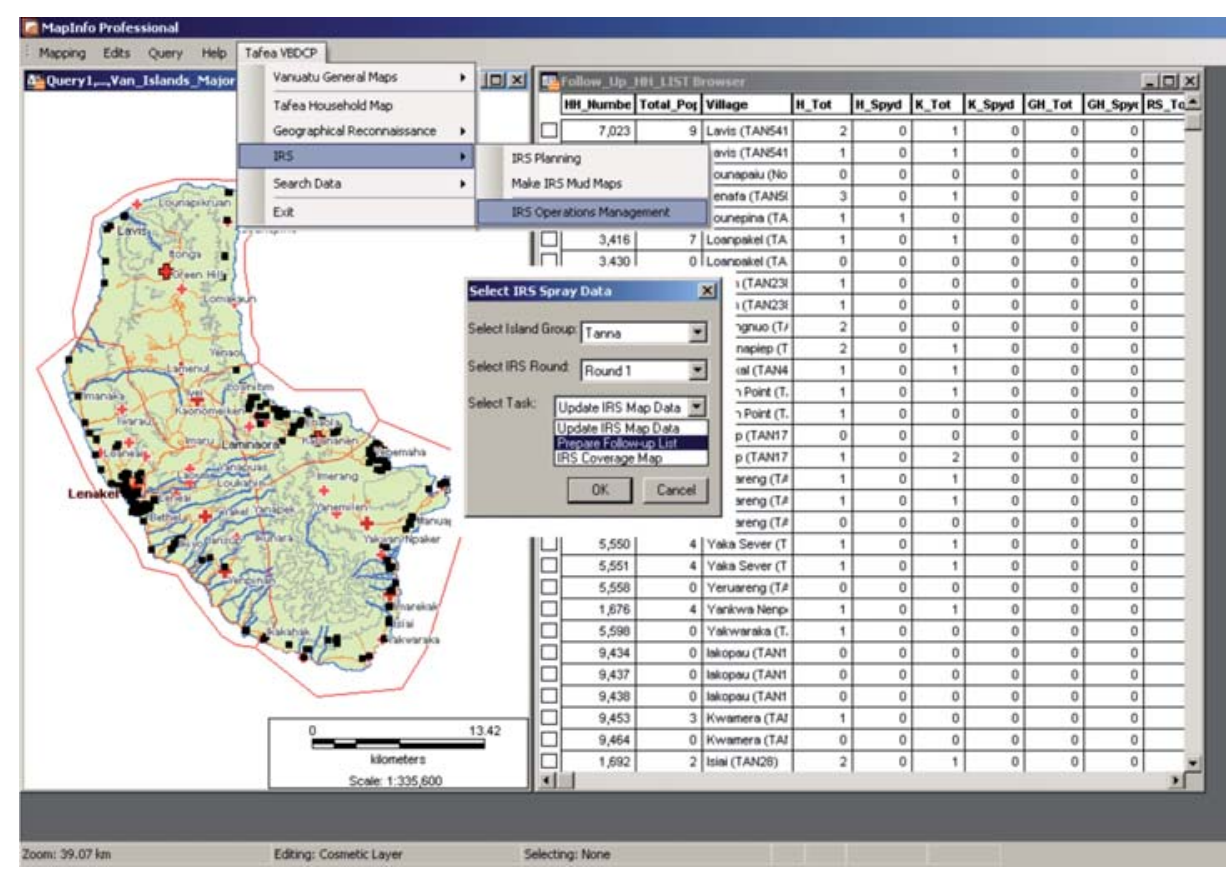

Fig. 5. Screenshot of the IRS household follow-up SDSS application.

Table 5. Reasons households were not sprayed at the completion of IRS.

\begin{tabular}{lc}
\hline Reason & Total households \\
\hline Refusal & 75 \\
Locked house & 73 \\
Inaccessible & 5 \\
Sick resident & 4 \\
Food store/canteen & 20 \\
Other & 15 \\
Total & 192 \\
\hline
\end{tabular}

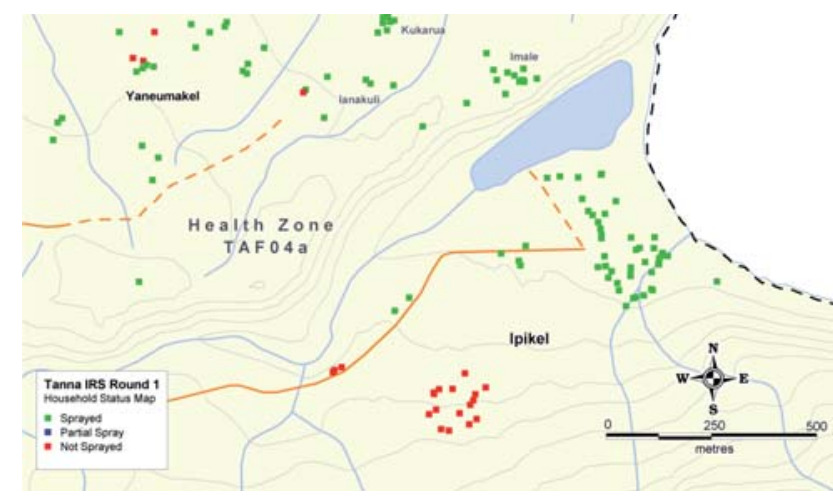

Fig. 6. Example Tanna Island IRS household status map at a sub-village scale.

Table 6. SDSS user acceptability survey response summary data.

\begin{tabular}{|c|c|c|c|c|c|}
\hline Survey Question & $\begin{array}{l}\text { Strongly } \\
\text { agree }\end{array}$ & Agree & Undecided & Disagree & $\begin{array}{l}\text { Strongly } \\
\text { disagree }\end{array}$ \\
\hline The SDSS provides a useful tool for planning IRS activities & $\begin{array}{c}100 \% \\
(12)\end{array}$ & $\begin{array}{c}0 \% \\
0\end{array}$ & $\begin{array}{c}0 \% \\
0\end{array}$ & $\begin{array}{c}0 \% \\
0\end{array}$ & $\begin{array}{c}0 \% \\
0\end{array}$ \\
\hline $\begin{array}{l}\text { The SDSS provides a useful tool for monitoring IRS and } \\
\text { supporting follow-up operations }\end{array}$ & $\begin{array}{c}100 \% \\
(12)\end{array}$ & $\begin{array}{c}0 \% \\
0\end{array}$ & $\begin{array}{c}0 \% \\
0\end{array}$ & $\begin{array}{c}0 \% \\
0\end{array}$ & $\begin{array}{c}0 \% \\
0\end{array}$ \\
\hline $\begin{array}{l}\text { The SDSS is useful for generating IRS status reports and } \\
\text { maps at the completion of operations }\end{array}$ & $\begin{array}{c}100 \% \\
(12)\end{array}$ & $\begin{array}{c}0 \% \\
0\end{array}$ & $\begin{array}{c}0 \% \\
0\end{array}$ & $\begin{array}{c}0 \% \\
0\end{array}$ & $\begin{array}{c}0 \% \\
0\end{array}$ \\
\hline $\begin{array}{l}\text { The SDSS and mapping applications were easy to } \\
\text { understand and use }\end{array}$ & $\begin{array}{l}75 \% \\
(9)\end{array}$ & $\begin{array}{c}17 \% \\
(2)\end{array}$ & $\begin{array}{l}8 \% \\
(1)\end{array}$ & $\begin{array}{c}0 \% \\
0\end{array}$ & $\begin{array}{c}0 \% \\
0\end{array}$ \\
\hline $\begin{array}{l}\text { Household mud-maps are a useful tool to support IRS } \\
\text { in the field }\end{array}$ & $\begin{array}{c}100 \% \\
(12)\end{array}$ & $\begin{array}{c}0 \% \\
0\end{array}$ & $\begin{array}{c}0 \% \\
0\end{array}$ & $\begin{array}{c}0 \% \\
0\end{array}$ & $\begin{array}{c}0 \% \\
0\end{array}$ \\
\hline Household mud-maps are easy to interpret in the field & $\begin{array}{l}75 \% \\
(9)\end{array}$ & $\begin{array}{c}25 \% \\
(3)\end{array}$ & $\begin{array}{c}0 \% \\
0\end{array}$ & $\begin{array}{c}0 \% \\
0\end{array}$ & $\begin{array}{c}0 \% \\
0\end{array}$ \\
\hline $\begin{array}{l}\text { The SDSS is a more effective tool to coordinate IRS than } \\
\text { traditional planning and reporting mechanisms }\end{array}$ & $\begin{array}{l}92 \% \\
(11)\end{array}$ & $\begin{array}{l}8 \% \\
(1)\end{array}$ & $\begin{array}{c}0 \% \\
0\end{array}$ & $\begin{array}{c}0 \% \\
0\end{array}$ & $\begin{array}{c}0 \% \\
0\end{array}$ \\
\hline
\end{tabular}




\section{Discussion}

This paper presents an innovative approach currently adopted in Vanuatu that utilises advancements in digital geo-spatial mapping technologies to coordinate and monitor an IRS intervention within a malaria elimination zone. Development of the SDSS for IRS focused on building from and utilising the existing geospatial household data collected during previous GR surveys. Key facets of the IRS intervention individually considered in the SDSS design included planning, implementation, monitoring and reporting. Programme management priorities during focal IRS operations reflected the challenges of implementing a scaled-up elimination intervention in the context of a remote Pacific island, where access to resources and infrastructure are limited. As such, priorities focused on the need for efficient resource allocation, effective service delivery (i.e. maximizing household spray coverage), and a high resolution yet user-friendly approach to monitoring, evaluation, surveillance and reporting.

During the planning phase, the interactive mapping interface enabled VBDCP personnel to visualize the distribution of households within the target area in relation to terrain and other logistical factors such as access and transport infrastructure. Based on these characteristics, the IRS target zone was broken down into the 21 manageable operation areas. Data generated for each area (Table 2) provided a basis for the development of operational timeframes, allocation of transport, and the geographical targeting of key resources, including insecticide, spray equipment and personnel to designated locales. In remote regions, where access is limited, the ability to accurately estimate resource requirements prior to deployment is essential to avoid logistical shortcomings such as the inadequate supply of equipment and manpower.

As IRS is also a method of community protection, maximum impact on malaria transmission is achieved by reaching the highest level of coverage possible (WHO, 2006). Data presented in the results indicate that IRS coverage across the target area in Tanna was high, suggesting an overall effective implementation of the intervention. Similarly, insecticide dosage rates calculated by average household surface area estimates and total insecticide used also provides a preliminary indication of an overall effective spray application during the first-round IRS.

Spatial coverage data illustrated no significant heterogeneity that could have led to remaining pockets of transmission. In the context of malaria elimination, it is essential to ensure that service delivery within the target area is uniformly distributed to minimise the potential for sustained transmission. Traditionally, malaria endemic countries with weak health information systems have had limited capacity to promptly and effectively measure the progress and spatial distribution of interventions. Through the automated mapping and reporting of IRS status by household within the SDSS, program managers were able to interactively monitor the progress and visualise the spatial distribution of coverage during implementation, without the need for complex statistical analysis. The ability to view IRS status at a detailed level and automatically extract associated household data for immediate follow-up response provides an effective operational tool to ensure coverage is both maximised and evenly distributed.

Data generated by the SDSS at the completion of the first-round IRS pertaining to households not sprayed (Table 5) provides useful information supporting the malaria elimination programme. These data, coupled with the IRS coverage distribution maps produced at a sub-village scale (as illustrated in Fig. 6), can enable programme managers to identify trends in service delivery such as clusters of locked households or refusals. This provides a mechanism to assess indicators such as the effectives of IRS notification campaigns and the operational performance of individual spray teams. Additionally, these data can be used to strategically plan and target further response measures such as community-based awareness and behaviour change communication (BCC) interventions in appropriate geographical regions.

As direct interaction with the SDSS interface is generally only relevant to information officers, programme managers and supervisors; the quantity of user acceptability survey data collected was limited. However, raw data collected from these surveys in both Vanuatu and the Solomon Islands still demonstrates a high user acceptability of the SDSS, with $100 \%$ of respondents highlighting its usefulness as an operational tool for the planning, implementation, monitoring and evaluation of IRS interventions. While we acknowledge that the small sample size prohibits meaningful statistical analysis and limits the ability to draw conclusions, the results of the acceptability study are encouraging. The high acceptability of the SDSS is reflected in the readoption and expansion of the SDSS as the primary operational tool to guide subsequent IRS interventions in Tafea province, other malaria control provinces in Vanuatu, and focal IRS operations in the neighbouring Solomon Islands. Both countries have now also 
expanded the SDSS framework to support additional frontline elimination interventions including universal household distribution of long-lasting insecticidal nets (LLINs).

Constraints of this field study are largely related to paper-based data entry and included minor lag time from field operations to digital data entry, and data entry formatting errors. To mitigate these constraints, hardcopy checklists were collected from the IRS field teams regularly and digital data entry field formats were locked. However, it is commonly indicated in the literature that hand-held data entry technology such as Personal Digital Assistant (PDAs) and mobile phones for field-based survey is cost-effective (Forster et al., 1991; Fletcher et al., 2003; Shirima et al., 2007; Yu et al., 2009). Should resources such as digital hand-held units be available, the potential to integrate such technology into an SDSS operational management framework would further increase reporting efficiency and provide programme managers with detailed indicative data in real-time. Additionally, it is anticipated that the expanding array of open-source and web-based geospatial applications becoming available today will ensure that the accessibility of geospatial decision making support tools for malaria elimination, public heath, and health planning in general will continue to grow.

A major focus in the development of the SDSS was the provision of provincially based public health workers with a user-friendly, yet powerful GIS-based operational tool that could support all phases of programme implementation and be operated independently by the field-based decision makers themselves. When used as part of a scaled-up frontline malaria elimination strategy, targeted vector-control activities such as IRS require sensitive tools to spatially monitor and evaluate intervention coverage to ensure maximum efficacy and universal service delivery is achieved. The employment of a SDSS during the first round of IRS in Tanna provided the Tafea VBDCP programme with a tool to guide all key facets of the intervention at the level of detail required for malaria elimination. The geo-spatial framework provided a user-friendly approach to visualize and breakdown the IRS target zone into manageable operation areas and extract detailed information to support the planning, implementation, monitoring and evaluation of the intervention. Additionally, the SDSS provided a visual and effective mechanism to assess service delivery, identify potential gaps and strategically target responsive measures to relevant geographic locations. This framework now also provides a foundation for the future integration and geo-referencing of additional programme data, including entomology, mobility and malaria case data. Through the incorporation of IRS household data with GR, additional intervention and other programme data, the SDSS framework provides an effective building block for the continuous development of a geographical-based malaria elimination household intervention database. It is anticipated the SDSS principles adopted in Vanuatu will be expanded to not only continue supporting future malaria elimination priorities in the Pacific such as targeted geospatial surveillance, rapid response and case investigation, but also be used as an interactive geospatial decision support framework for the broader health sector in general.

\section{Acknowledgements}

We would like to thank all of the individuals from the Vanuatu VBDCP and community volunteers who assisted with the IRS fieldwork on Tanna Island, particularly the leadership of James Iaviong and Rueban Sumaki. We would also like to thank the PacMISC provincial programme support officer Megan Johnson for her administrative support throughout the IRS campaign. Additionally, we would like to thank the survey participants from the Solomon Islands VBDCP. Finally, we thank the chiefs and communities of Tanna Island for their continued participation, cooperation and overwhelming support in these operations and the malaria elimination programme in general. A.C.A. Clements is supported by a Career Development Award from the Australian National Health and Medical Research Council (\#631619).

\section{References}

Clements AC, Barnett AG, Cheng ZW, Snow RW, Zhou HN, 2009. Space-time variation of malaria incidence in Yunnan province, China. Malar J 8, 180.

Daash A, Srivastava A, Nagpal BN, Saxena R, Gupta SK, 2009. Geographical information system (GIS) in decision support to control malaria-a case study of Koraput district in Orissa, India. J Vector Borne Dis 46, 72-74.

Feachem RGA, Phillips AA, Hwang J, Cotter C, Wielgosz B, Greenwood BM, Sabot O, Rodriguez MH, Abeyasinghe RR, Ghebreyesus TA, Snow RW, 2010. Shrinking the malaria map: progress and prospects Lancet 376, 1566-1578.

Feachem RGA, Phillips AA, Targett GA (Eds), 2009. Shrinking the malaria map: a prospectus on malaria elimination. San Francisco, The Global Health Group, Global Health Sciences, University of California, $187 \mathrm{pp}$.

Fletcher LA, Erickson DJ, Toomey TL, Wagenaar AC, 2003. Handheld computers. A feasible alternative to paper forms for 
field data collection. Eval Rev 27, 165-178.

Forster D, Behrens RH, Campbell H, Byass P, 1991. Evaluation of a computerized field data collection system for health surveys. Bull World Health Organ 69, 107-111.

GMAP, 2008. The Global Malaria Action Plan, Roll Back Malaria Partnership, 271 pp.

Keenen PB, 2003. Spatial decision support systems. Decision making support systems achievements and challenges for the new decade. Morah M, Forgionne G, Gupta J, Hershey PA (Eds), Idea Group Publishing, pp. 28-39.

Kelly GC, Hii J, Batarii W, Donald W, Hale E, Nausien J, Pontifex S, Vallely A, Tanner M, Clements A, 2010. Modern geographical reconnaissance of target populations in malaria elimination zones. Malar J 9, 289.

Kerouedan D, 2010. The Global Fund to fight HIV/AIDS, TB and Malaria 5-y: evaluation policy issues. Bull Soc Pathol Exot 103, 119-122.

Likert R, 1932. A technique for the measurement of attitudes. Arch Psych 140, 1-55.

Lozano-Fuentes S, Elizondo-Quiroga D, Farfan-Ale JA, LoronoPino MA, Garcia-Rejon J, Gomez-Carro S, Lira-Zumbardo V, Najera-Vazquez R, Fernandez-Salas I, Calderon-Martinez J, Dominguez-Galera M, Mis-Avila P, Morris N, Coleman M, Moore CG, Beaty BJ, Eisen L, 2008. Use of Google Earth to strengthen public health capacity and facilitate management of vector-borne diseases in resource-poor environments. Bull World Health Organ 86, 718-725.

Reid H, Haque U, Clements AC, Tatem AJ, Vallely A, Ahmed SM, Islam A, Haque R, 2010. Mapping malaria risk in Bangladesh using Bayesian geostatistical models. Am J Trop Med Hyg 83, 861-867.

Shirima K, Mukasa O, Schellenberg JA, Manzi F, John D, Mushi A, Mrisho M, Tanner M, Mshinda H, Schellenberg D, 2007. The use of personal digital assistants for data entry at the point of collection in a large household survey in southern Tanzania. Emerg Themes Epidemiol 4, 5.

Srivastava A, Nagpal BN, Joshi PL, Paliwal JC, Dash AP, 2009. Identification of malaria hot spots for focused intervention in tribal state of India: a GIS based approach. Int J Health Geogr 8,30 .

The malERA Consultative Group on Health Systems Operational Research, 2011. A research agenda for malaria eradication: health systems and operational research. PLoS Med 8, e1000397.

The malEra Consultative Group on Monitoring Evaluation and Surveillance, 2011. A research agenda for malaria eradication: monitoring, evaluation, and surveillance. PLoS Med 8, e1000400.

The Pacific Malaria Initiative Survey Group on behalf of the Ministries of Health of Vanuatu and Solomon Islands, 2010. Malaria on isolated Melanesian islands prior to the initiation of malaria elimination activities. Malar J 9, 218.

UNICEF/UNDP/World Bank/WHO, 2010. Special Programme for Research \& Training in Tropical Diseases (TDR). Retrieved 08/09/2010, 2010, from http://apps.who.int/ tdr/svc/topics/health-systems-implementation-research.

Vitoria M, Granich R, Gilks CF, Gunneberg C, Hosseini M, Were W, Raviglione M, De Cock KM, 2009. The global fight against HIV/AIDS, tuberculosis, and malaria: current status and future perspectives. Am J Clin Pathol 131, 844-848.

WHO, 2006. Indoor residual spraying. Use of indoor residual spraying for scaling up global malaria control and elimination. World Health Organization, Geneva, Switzerland, pp. 10.

WHO, 2007. Malaria elimination - a field manual for low and moderate endemic countries. World Health Organization, Geneva, Switzerland, pp. 85.

WHO, 2009. WHO recommended insecticides for indoor residual spraying against malaria vectors. Retrieved at http://www.who.int/whopes/Insecticides_IRS_Malaria_09.pdf. (accessed on January 2011).

WHO, 2009. World Malaria Report 2009. World Health Organization, Geneva, Switzerland.

Yu P, de Courten M, Pan E, Galea G, Pryor J, 2009. The development and evaluation of a PDA-based method for public health surveillance data collection in developing countries. Int J Med Inform 78, 532-542. 